\title{
The pathogenesis of the neurological complications of HIV-1 infection
}

\author{
Bruce James Brew
}

HIV-1 infection is complicated not infrequently by a number of sequelae that may involve the central and peripheral nervous systems even in the absence of opportunistic infections and neoplasms. Chief among these disorders are AIDS dementia complex, vacuolar myelopathy, peripheral neuropathy and myopathy as well as other less well appreciated complications such as seizures and transient ischaemic attacks. ${ }^{1}$ This review will explore the various possible explanations of such complications after a brief discussion of each entity.

\section{Aids dementia complex (ADC)}

This complication is known under a variety of terms such as HIV-1 encephalopathy, subacute encephalitis, AIDS related dementia and more recently HIV-1 associated cognitive/ motor deficit. ${ }^{2}$ To understand various pathogenetic considerations it is first necessary to outline the critical features of the disorder: its broad clinical features, the timing of the dementia, the results of investigations and the effects of treatment.

While some controversy exists as to whether the disorder is consistently a cortical or subcortical dementia because of the recent demonstration of cortical neuronal loss, ${ }^{3-5}$ the clinical (rather than pathological) presentation of the patients is dominantly that of a subcortical process where there are complaints of poor concentration, disturbed short term memory, slowing of thought processes with motor incoordination and gait unsteadiness. ${ }^{6}$ Behavioural symptoms such as social apathy and withdrawal are less common and have a correlation with the severity of $\mathrm{ADC}$ that is similar to other disturbances such as limb tremor and urinary urgency (unpublished data). So called cortical symptoms such as aphasia, alexia and agraphia are distinctly unusual in ADC and when they do occur, they do so at an advanced stage of dementia where the deficit has become more global. $\mathrm{ADC}$ is most often a complication occurring at the phase of moderately advanced immunosuppression. In a personally examined group of $\mathrm{ADC}$ patients, the mean $\mathrm{CD} 4$ cell count was 94, SD 139 (unpublished data). Numerous other investigators have also observed its relatively late occurrence.

Investigations often reveal a number of abnormalities that are confirmatory of the diagnosis rather than diagnostic. Computed tomography (CT) of the brain often shows cerebral atrophy and magnetic resonance imaging of the brain may show periventricular T2 weighted abnormalities. ${ }^{78}$ Single photon emission computed tomography (SPECT) usually shows multifocal cortical and subcortical areas of hypoperfusion. ${ }^{9}$ Preliminary data suggest that SPECT is more sensitive than the other imaging techniques ${ }^{10}$; however, similar changes may occur very frequently in asymptomatic patients. ${ }^{11}$ At a more investigational level, positron emission tomography reveals hypometabolism of the basal ganglia early in the disease only to be replaced by global hypoactivity late in the illness. ${ }^{12}$ Similarly, water suppressed proton magnetic resonance spectroscopic imaging shows significantly reduced $\mathrm{N}$-acetylaspartate relative to choline and creatine in approximately $40 \%$ of cognitively impaired patients although there was overlap with asymptomatic patients. ${ }^{13}$

Just as various imaging techniques may reveal abnormalities in asymptomatic patients so too may cerebrospinal fluid (CSF) analysis where a host of disturbances may be found. These include a mononuclear pleocytosis, raised protein, oligoclonal bands, intrathecal IgG synthesis ${ }^{14-18}$ raised $\beta_{2}$ microglobulin and neopterin concentrations. ${ }^{19-22}$ Of these, the latter two have been shown to be related to the severity of ADC as have the CSF concentrations of the excitotoxin quinolinic acid. ${ }^{23}$ Other markers of immune activation such as tumour necrosis factor ${ }^{24} 25$ remain controversial. Interleukins $1 \beta$ and 6 have also been associated with both HIV-1 infection per se and with the presence but seemingly not the severity of ADC. ${ }^{24}$ Recently, anti-myelin basic protein antibodies have also been found to be elevated in the CSF of patients with ADC but there does not appear to be a relationship between the degree of elevation and the severity of $\mathrm{ADC} .{ }^{26}$

With regard to the virological aspects of the CSF, the detection of $\mathrm{p} 24$, the core antigen of HIV-1, is quite specific but insensitive $^{27} 28$ with approximately half of patients with severe ADC not having demonstrable p24 despite acid dissociation of immune complexes to remove any p24 that may have been "trapped". Thus far no one has been able to measure other viral antigens in the CSF such as $g p 120$, nef and tat. Culture of HIV-1 from the CSF is also non-specific with approximately $30 \%$ of patients being culture positive despite the absence of cognitive abnormalities. $^{29}$ As patients become more demented the ability to rescue HIV-1 from the CSF increases but does not exceed
B J Brew

Accepted for publication 16 June 1993
HIV Epidemiology and Clinical Re

Darlinghurst, Sydney, 
approximately $50 \%$ despite the presence of severe ADC. ${ }^{28}$ Amplification of HIV-1 by the polymerase chain reaction from the CSF has also been explored but at the present time its utility is controversial as some groups have claimed that HIV-1 can only be amplified from patients who are neurologically abnormal whereas others have found the opposite. ${ }^{30} 31$

Neurophysiological investigations may also be abnormal but again the underlying theme is that the abnormalities are often found in asymptomatic patients as well as those with ADC albeit in a less severe form. Thus disturbances in pursuit and saccadic eye movements become increasingly common with severity of systemic disease and with the presence of ADC. ${ }^{32-34}$ Brainstem auditory evoked potentials have similarly been found abnor$\mathrm{mal}^{35}{ }^{36}$ as well as long latency event related potentials. ${ }^{37}$ The significance of electroencephalographic (EEG) abnormalities is, however, less clear. Two studies have described an increased frequency of EEG abnormalities in asymptomatic patients ${ }^{36} 38$ but a larger and more rigorously controlled study has not supported these earlier findings. ${ }^{39}$ Moreover, the purported prognostic significance of EEG abnormalities in asymptomatic patients is presently only supported by one group..$^{38}$

The neuropathology of ADC has recently been revised and by consensus ${ }^{40}$ it may be divided into five categories which in individual cases frequently overlap with each other. ${ }^{3-541-47}$ The most common disorder in this classification is HIV-1 leukoencephalopathy where there is diffuse damage to the white matter, reactive astrocytosis, macrophages and multinucleated giant cells with minimal or no inflammatory infiltrates. These changes are predominantly subcortical in location and may be found in patients who are mildly demented. However, a similar leukoencephalopathy where evidence of HIV1 infection in the brain tissue is absent is not addressed by this consensus classification because of the lack of definite association with HIV-1 infection. Nonetheless, the disorder occurs frequently in patients with ADC Diffuse poliodystrophy is also a reasonably common finding and is defined as the presence of diffuse reactive astrogliosis and microglial activation involving cerebral grey matter. The clinical correlate of this pathology has yet to be determined but it would seem likely to at least be associated with mild $\mathrm{ADC}$. Less frequent is $\mathrm{HIV}$ encephalitis where there are perivascular inflammatory infiltrates of multinucleated giant cells again in a predominantly subcortical distribution. This finding correlates with the presence of significant ADC. Rarely, the pathology may be characterised by vacuolation throughout the white matter which has been termed vacuolar leukoencephalopathy, the clinical correlate of which has yet to be delineated. Lastly, cerebral vasculitis has been described ${ }^{48} 49$ but it would appear to be distinctly uncommon. The relationship between cortical atrophy with neuronal loss ${ }^{3-5}$ and the above neuro- pathological sets is presently unclear although it is most likely associated with HIV diffuse poliodystrophy and HIV encephalitis. Moreover the precise interrelationships between the latter mentioned sets is unknown but it would seem that leukoencephalopathy forms a base upon which are added the changes of diffuse poliodystrophy and in moderate to severe cases of ADC, HIV encephalitis. The overriding principle, however, is that the neuropathological changes are dominantly subcortical and even within these subcortical areas there appears to be certain structures that are more commonly involved. Thus several investigators have noted the prominent basal ganglia involvement, especially the globus pallidus. ${ }^{45} 50$ Importantly, at least two researchers have noted that the distribution of pathology is inconsistent with a simple "centrifugal" spread of disease from the meninges. ${ }^{4045}$

ADC can be treated successfully with zidovudine and possibly other nucleosides. While there is some controversy as to the optimal dose of $\mathrm{ZDV}$ for $\mathrm{ADC}$ there is no doubt that it improves and sometimes reverses cognitive impairment. ${ }^{51-53}$ Similarly, there is some evidence for the efficacy of didanosine at least in children ${ }^{54}$ although preliminary analysis of the efficacy of didanosine in adults has cast some doubt as to whether there is any significant effect (Portegies, personal communication). However, despite the encouraging reports of treatability of $\mathrm{ADC}$ it must be recognised that not all patients will respond to therapy even with zidovudine. The explanation for such variation in response is unknown but it may relate to resistance to the particular drug, inadequate penetration of the drug through the blood brain barrier and possibly the nature of a particular strain of virus; for example, the syncytium inducing virus strain is purported to be relatively insensitive to zidovudine or to develop drug resistance more rapidly..$^{55}$ Furthermore, the precise neuropathological features of $\mathrm{ADC}$ that may or may not respond to treatment are unknown save for preliminary data showing that multinucleated cell changes and HIV leukoencephalopathy have become less frequent since the introduction of zidovudine. ${ }^{56} 57$

With the latter background, it is possible to approach some pathogenetic considerations of HIV-1 brain involvement that serve as a base for the construction of a theoretical model. Firstly, subclinical involvement of the nervous system is common throughout the long course of HIV-1 infection as delineated by a number of investigators approaching the issue from different aspects. Minor neuropsychological dysfunction has been found by several groups in the absence of any symptoms ${ }^{5859}$ while other larger studies have not shown any significant deficit at a population level. ${ }^{76061}$ Frequent abnormalities in the CSF of asymptomatic patients have also been described with a mild mononuclear pleocytosis usually of less than 100 mononuclear cells, an elevated protein ${ }^{16}$ and recovery of HIV-1 
from the CSF in a small percentage of patients and rarely $\mathrm{p} 24$, the core protein of HIV-1. ${ }^{1762}$ As previously mentioned, disturbances of neurophysiological function, EEG abnormalities long latency potentials and eye movement disturbances have also been found by a number of authors. Imaging studies of the brain have also delineated the presence of abnormalities by a number of different techniques in asymptomatic patients. Perhaps even more important than the wealth of data indirectly indicating central nervous system disturbance is the recent finding of neuropathological changes in the brains of patients who had been asymptomatically infected and who died accidental deaths. ${ }^{63}$ While there was no evidence of productive HIV-1 infection of the brain, there were changes of astrogliosis, vasculitis and a lymphocytic meningitis.

Secondly, although there is subclinical involvement by HIV-1 throughout the course of HIV-1 infection, the clinical expression of this involvement, namely $\mathrm{ADC}$, is largely a feature of advanced HIV-1 disease when there is significant immunodeficiency. This is supported by earlier studies ${ }^{64}$ and by our more recent study where we found the mean CD4 cell count of patients with ADC was 94 SD 139 (unpublished data). Thus ADC is essentially an opportunistic complication of HIV-1 disease.

Thirdly, despite significant immunodeficiency, not every HIV-1 infected individual develops ADC. Prevalence figures vary for $\mathrm{ADC}$ as already mentioned but even before the introduction of zidovudine, prevalence estimates were not higher than approximately $66 \%$. While one explanation may be that the majority of patients are not living long enough to develop ADC, this seems unlikely at least on an anecdotal level. Additionally, there is evidence for "neurotropism": most brain derived viral isolates from patients with HIV-1 encephalitis have been found to be macrophage tropic and it has been shown that HIV-1 will only replicate in microglia if it is macrophage tropic. ${ }^{65-69}$

Fourthly, there is a superficially paradoxical correlation between ADC severity and certain markers of immune activation (especially of $\gamma$ interferon), namely $\beta_{2}$ microglobulin, neopterin and quinolinic acid. ${ }^{19-23}$ Moreover, the presence of ADC has been linked to certain cytokines in the CSF namely interleukin 1 and $6 .{ }^{25}$ Hence, ADC is related to increased immune activity in the form of cytokines at a time when there is decreased humoral and cell mediated immune function. This is mirrored in the systemic circulation in AIDS where there is evidence for excessive activity of cytokines. ${ }^{21} 70$

Fifthly, the neuropathological changes are dominantly subcortical and perivascular in location with a specific vulnerability within those subcortical structures. ${ }^{41-4971}$ Additionally, there is cortical neuronal loss mainly affecting the frontal lobes. ${ }^{3-5}$ Moreover, there are certain parts of the brain that seem peculiarly susceptible to the patho- logical changes, namely the globus pallidus. ${ }^{42}$ Important from a pathogenetic view point is the absence of productive infection of the choroid plexus. ${ }^{425072}$ Just as there is topographic localization of the neuropathology of $\mathrm{ADC}$ so too is there regionalization of the virological features. Thus productive infection is largely a feature of subcortical structures in accord with several investigators ${ }^{42471}$ but in contrast to Gabuzda et al. ${ }^{73}$ The latter group, however, did not systematically sample the same areas as in the other studies and the number of samples was small. Indeed, there has been no large published study where cortical and subcortical tissues were examined that has shown that the cortex is preferentially infected over subcortical areas. The recent finding by several groups of cortical neuronal loss ${ }^{3-5}$ may therefore be an indirect consequence of subcortical infection as discussed by Achim et al. ${ }^{74}$ Moreover, the finding of Everall et $a l^{3}$ that cortical neuronal loss occurred independently of HIV-1 encephalitis and in some patients without ADC suggests that cortical neuronal loss and HIV-1 encephalitis may be independent processes that variably contribute to ADC.

The sixth critical point is that productive infection of the brain is restricted to the mononuclear and macrophage cells and microglia. There is still controversy as to whether endothelial cells and oligodendroglia are infected but it is likely that the early reports of endothelial cell infection actually represent infection of the microglia as substantiated by double labelling experiments ${ }^{71}$ and the recent finding that microglia are a component of the perivascular glial barrier. ${ }^{75}$ Whether oligodendroglial cells are infected is also still open to speculation. The initial reports of such infection ${ }^{76} 77$ were open to considerable doubt ${ }^{7879}$ but recent data from Esiri et $a l^{80}$ has raised the possibility again although if infection of oligodendroglial cells does occur in vivo it is distinctly uncommon. Similarly, while most investigators agree that astrocytes can be infected in vitro ${ }^{81-83}$ the infection is low grade and mediated independent of the CD4 receptor and probably by way of galactosyl ceramide. ${ }^{84}$ How this relates to in vivo infection is entirely unclear but it would appear to have limited relevance since galactosyl ceramide is most abundant on oligodendroglial cells, the very cell type that at best is infected only very infrequently.

The seventh major point is that there is a clinical-virological dissociation in that the clinical severity of ADC is often greater than amount of productive HIV-1 infection found at necropsy. ${ }^{50} 85$ Indeed, in some cases of paediatric $A D C$ there is no evidence of infection despite the presence of severe dementia. ${ }^{86}$ Moreover, there is viral-pathological dissociation wherein the pathology is more extensive than the amount of productive infection. ${ }^{50} 85$ While high levels of unintegrated HIV-1 DNA have been found in the brains of patients with ADC in one study ${ }^{87}$ only a small number of patients was studied and these all had severe ADC. Preliminary data from 
Gadler et $a l^{88}$ suggest that latent infection in the brains of $\mathrm{ADC}$ becomes more frequent with increasing $\mathrm{ADC}$ severity but that in less severe cases of ADC there may be little detectable latent infection.

The latter considerations can be summarised as follows: (i) the brain is involved early by HIV-1, (ii) there is selectivity of involvement in terms of the patient, the brain structures and the brain cells, (iii) direct viral infection of the brain is not the explanation of the clinical deficit, (iv) host mediated responses seem likely as candidate toxins and (v) certain viral products are involved in tissue damage.

With these considerations it is possible to construct an hypothetical model of the pathogenesis of ADC. It is proposed that HIV-1 enters the brain early in the course of the disease probably at the time of seroconversion. Entry is by way of blood borne infection and to a lesser extent by "spread" from chronic meningeal infection which in turn is likely related to low level infection of the choroid plexus. The latter is supported by experimental evidence showing that the choroid plexus may be infected..$^{72}$ That productive infection of the choroid plexus cannot be demonstrated in patients with ADC is probably the result of the death of the original cells capable of supporting infection. Such low level infection is kept in check by a relatively intact immune system but as HIV-1 disease progresses, brain infection becomes unchecked and compensatory mechanisms are activated that result in the production of various cytokines that over time lead to central nervous system dysfunction. Additionally, the low level brain infection is now capable of being amplified by the similarly unchecked systemic disease thereby accounting for the perivascular distribution to the pathology of ADC. The tissue damaged by the cytokines then becomes secondarily infected both by the now unchecked local brain infection and by the systemically circulating infected cells. Moreover, as HIV-1 disease advances and there is a reduction in CD4 + cells there is a selection towards macrophage tropic isolates of HIV-1 that further infect the brain: essentially the brain cells that are of macrophage lineage namely the microglial cells. However, it should be stressed that macrophage tropism alone is insufficient to explain brain tissue invasion by HIV-1. ${ }^{89}$ The mechanism by which HIV-1 actually enters the brain is still conjectural but there are at least two possibilities, namely through trafficking of activated $T$ cells, the so called "Trojan horse" mechanism, ${ }^{90} 91$ since these have been shown to be able to cross the blood-brain barrier. As well, since the blood brain barrier is disrupted in advanced HIV-1 disease $^{9293}$ cells harbouring HIV-1 and cell free virus could easily pass into the brain.

At the cellular level, the envelope glycoprotein of HIV-1 gp120 is toxic to rodent neurons $^{94}$ and the neuronal killing is critically dependent upon the presence of cells of the macrophage lineage. ${ }^{95}$ Furthermore, the precise mechanism of neuronal damage is by way of activation of the N-methyl D-aspartate receptor with consequent influx into the cell of calcium and secondary synthesis of nitric oxide in those neurons containing nitric oxide synthetase. ${ }^{96}$ Not only do macrophage lineage cells serve to facilitate neuronal damage but it appears that they release neuronotoxic factors as well. Some of these are as yet undefined, ${ }^{97}$ while others are arachidonic acid metabolites and platelet activating factor, that require cell-to-cell interactions for toxicity. ${ }^{98}$ Our group has also shown that quinolinic acid, an $\mathrm{N}$-methyl $\mathrm{D}$-aspartate receptor agonist, is elevated in the CSF of $A D C$ patients ${ }^{23}$ and that in vitro HIV-1 infected macrophages can produce large quantities of quinolinic acid with this production being dependent upon the degree of macrophage tropism of HIV-1.99 100

While these mechanisms serve to assist in understanding the pathogenesis of neuronal loss and dysfunction, they do not address the causation of the leukoencephalopathy. At present, it seems likely that the cerebral white matter is affected by the cytokines that are released by macrophage lineage cells in an attempt to control infection. Certainly similar leukoencephalopthic changes have been observed in patients receiving high doses of various cytokines as part of cancer chemotherapy. Another possible mechanism is the documented methylation defect ${ }^{101}$ in HIV-1 infected individuals that may lead to changes similar to cyanocobalamin deficiency. The third possibility, namely direct infection of oligodendrocytes, would seem to be unlikely as previously discussed and if present to be of minor significance.

\section{Vacuolar myelopathy}

Approximately one third of patients ${ }^{102}$ have a myelopathy usually manifesting as a spastic paraparesis without a definite sensory level although posterior column type sensory loss namely, proprioception and vibration disturbance is prominent. The disorder is largely confined to the legs and has a subacute to chronic onset over weeks to months leading on occasion to a wheelchair bound state. In most patients the myelopathy is associated with ADC. Importantly, vacuolar myelopathy is exceptionally uncommon in children who are HIV-1 infected. ${ }^{103}$

Pathologically there are multiple vacuoles in the white matter of the posterior and lateral columns of the spinal cord, infrequent lipid-laden macrophages and separation of the myelin lamellae on electron microscopy. Despite the similarities with subacute combined degeneration of the cord serum vitamin B12 levels are normal. Recent studies have demonstrated that this disorder is probably not the result of productive HIV-1 infection $^{104105}$ although controversy still exists. ${ }^{106}{ }^{107}$ It is conceivable, however, that the latter studies may have focused on cases with combined multinucleated cell myelitis and vacuolar myelopathy since the two conditions frequently coexist. ${ }^{41}$ Multinucleated cell myelitis is characterised by multinucleated 
cell infiltrates and is related to productive viral infection. Response of either of these disturbances to antiretroviral therapy is unknown but anecdotal experience suggests that vacuolar myelopathy does not respond while multinucleated cell myelitis does.

The pathogenesis of vacuolar myelopathy is unclear. Three possibilities exist namely, that it is (i) related to HIV-1 infection per se, (ii) secondary to another opportunistic infection and (iii) related to a metabolic abnormality. As to the first possibility, it would seem unlikely to be secondary to productive infection if one excludes multinucleated cell myelitis. Moreover, the recent report describing vacuolar myelopathy in immunocompromised non-AIDS patients strongly points away from HIV-1 per se being pathogenetically important. ${ }^{108}$ Nonetheless, other retroviruses such as human T-lymphotropic virus type I have been associated with a myelopathy ${ }^{109} 110$ as has human T-lymphotropic virus type II. ${ }^{111} 112$ The possibility that vacuolar myelopathy might be related to dual infection with HTLV-I has been excluded. ${ }^{113}$ The second possibility that it is related to another opportunistic infection is conceivable considering that the disorder is so uncommon in children just as opportunistic infections in general are. ${ }^{103}$ The third possibility namely that it is secondary to an underlying metabolic abnormality is also conceivable as a methylation defect has been identified in HIV infection. ${ }^{101}$ However, this abnormality has also been described in HIV infected children $^{114}$ the very group where vacuolar myelopathy is rare.

\section{Peripheral neuropathy}

HIV-1 related peripheral neuropathy may take the form of mononeuritis multiplex, inflammatory demyelinating polyneuropathy, autonomic neuropathy and distal symmetrical polyneuropathy. ${ }^{115}$ The AAN working group has, however, only defined two conditions: HIV-1 associated acute inflammatory demyelinating polyneuropathy, HIV-1 associated predominantly sensory neuropathy. ${ }^{2}$ Mononeuritis multiplex occurs in the context of a mild immunodeficiency ${ }^{116}$ and seems no different than its non HIV counterpart. It is important to distinguish this type of mononeuritis that occurs relatively early in HIV disease as opposed to mononeuritis that occurs late in HIV disease where the aetiology is almost certainly cytomegalovirus infection. ${ }^{117}$ Similarly, an inflammatory demyelinating neuropathy may occur acutely or chronically in the context of seroconversion to $\mathrm{HIV}^{118}$ or at a more advanced stage of HIV disease. Its features are no different from its non HIV counterpart with the exception of the finding of a CSF pleocytosis, probably the result of concordance of two disease processes namely the neuropathy and "background" HIV related CSF abnormalities. ${ }^{119}$ The latter neuropathies have been studied pathologically and the consistent finding has been the lack of evidence of significant pro- ductive infection of the peripheral nerve ${ }^{118120}$; the only exception being a patient who had productive infection in endoneural infiltrates. Consequently, the pathogenesis of these neuropathies is considered most likely to be on an autoimmune basis. ${ }^{115}$

An autonomic neuropathy has also been described. ${ }^{121}$ Its clinical manifestations of bladder and bowel dysfunction, sweating abnormalities and arrhythmias occur infrequently although a subclinical autonomic neuropathy has been found in up to $50 \%$ of HIV infected patients. ${ }^{122}$ Because this neuropathy often occurs in conjunction with the distal symmetrical predominantly sensory neuropathy, pathogenetic possibilities for both disorders will be discussed together.

Probably the most important of the HIV related peripheral neuropathies is the distal predominantly sensory neuropathy. This is largely a feature of advanced HIV disease and is common occurring in approximately $45 \%$ of such patients. ${ }^{123} 124$ Patients complain of numbness which is usually confined to the lower legs; only rarely are the arms involved. Significant weakness of the legs is distinctly unusual. In a small proportion of patients a painful distal sensory neuropathy develops which advances to the point where walking is difficult. ${ }^{125}$

The pathogenesis of these neuropathies is also unclear. Productive infection of the nerve has not been convincingly demonstrated ${ }^{105} 126$ and although cytomegalovirus infection has been implicated in the pathogenesis of the distal painful sensory peripheral neuropathy on epidemiological grounds ${ }^{127}$ it is unlikely that cytomegalovirus is playing a significant role when one considers that the neuropathy may occur at a time when there is insufficient immunodeficiency for cytomegalovirus to be a pathogen. The significance of the rarity of peripheral neuropathy in HIV infected children is unknown but as with vacuolar myelopathy it may point to an indirect pathogenesis perhaps a metabolic disturbance or another opportunistic infection. A metabolic aetiology has support by way of the previously mentioned methylation defect that has been found in HIV infected patients. In a similar disturbance, abuse of nitrous oxide, the resulting methylation defect leads to a peripheral neuropathy and myelopathy. ${ }^{128}$ However, macrophages have been found to be prominent in the peripheral nerves of HIV infected patients arguing against a purely metabolic disturbance. ${ }^{129}$

\section{Myopathies}

HIV-1 related myopathy is still a poorly defined entity. Patients usually present with slowly progressive proximal weakness that seemingly may occur at any point in their HIV-1 disease. Excluding zidovudine related myopathy the pathological findings can be grouped as follows: an inflammatory myopathy that is similar to if not identical with polymyositis and a non-inflammatory myopathy. ${ }^{130} 131$ 
Pathogenetically, productive HIV-1 infection has not been found in the majority of studies with the exception of occasional evidence of infection of the infiltrating cells. ${ }^{115}$ Such data would seem to point away from a direct HIV-1 aetiology.

\section{Seizures}

Seizures may also complicate HIV-1 infection. ${ }^{132} 133$ They may be both partial and generalised although this author's experience is that they are most often generalised. Preliminary data indicate that they are largely a feature of moderately advanced HIV-1 disease and that there is an association with $\mathrm{ADC}$ (6, unpublished observations). The pathogenesis of such seizures at the moment is entirely conjectural but in view of the association with $\mathrm{ADC}$ it would seem that the role of excitotoxins in both disorders may be important Lipton. ${ }^{134}$

\section{Transient neurological deficits and strokes}

Transient ischaemic attacks in the absence of an underlying infection or neoplasm may occur in HIV-1 infection. ${ }^{135} 136$ These usually do not lead to clinically apparent strokes but at autopsy some $20 \%$ of patients have evidence of small areas of infarction in the basal ganglia. ${ }^{137}$ The pathogenesis of these vascular events is unknown but there is an association with anticardiolipin antibodies. ${ }^{136} 138$

\section{Conclusion}

Thus the pathogenesis of HIV-1 related neurological involvement is complex and likely to be multifactorial. There is overwhelming evidence that the myriad of neurological complications is not simply a result of the viral burden of productive infection but more probably there is a complex interplay of cytokines, excitotoxins, toxic viral products such as gp120 and in some cases autoimmunity.

1 Brew BJ. Central and peripheral nervous system abnormalities in HIV-1 infection. In: White DA, Gold JWM eds: Medical Management of AIDS Patients. Medical eds: Medical Management of AIDS Patients. Medical Clinics of North Am

2 Report of a Working Group of the American Academy of Neurology AIDS Task Force. Nomenclature and research case definitions for neurologic manifestations of human immunodeficiency virus type 1 (HIV-1) infection. Neurology 1991;41:778-85.

3 Everall IP, Luthert PJ, Lantos PL. Neuronal loss in the frontal cortex in HIV infection. Lancet 1991;337: 1119-21.

4 Ketzler S, Weis S, Haug H, Budka $\mathrm{H}$. Loss of neurons in the frontal cortex in AIDS brains. Acta Neuropathol (Berl) 1990;80:92-94.

5 Wiley CA, Masliah E, Morey M, et al. Neocortical damage during HIV infection. Ann Neurol 1991;29:651-7.

6 Navia B, Jordan BD, Price RW. The AIDS dementia complex: I. clinical features. Ann Neurol, 1986;19: complex

7 McArthur JC, Cohen BA, Selnes OA, et al. Low prevalence of neurological and neuropsychological abnor malities in otherwise healthy HIV-1 infected individuals: Results from the multicentre AIDS cohor

8 Jarvik JG, Hesselink JR, Kennedy C, et al. Acquired immunodeficiency syndrome: magnetic resonance patterns of brain involvement with pathologic correlation. Arch Neurol 1988;45:731-6.

9 Masdeu JC, Yudd A, Van Heertum RL, et al. Single photon emission computed tomography in human immunodeficiency virus encephalopathy: a preliminary report. F Nuc Med 1991;32:1471-5.

10 Maini CL, Pigorini F, Pau FM, et al. Cortical cerebral blood flow in HIV-1 related dementia complex. Nuclear Medicine Communications 1990;11:639-48.

11 Schielke E, Tatsch K, Pfister HW, et al. Reduced cerebral blood flow in early stages of human immunodeficiency virus infection. Arch Neurol 1990;47:1342-5.

12 Rottenberg DA, Moeller JR, Strother SC, et al. The metabolic pathology of the AIDS dementia complex. metabolic pathology of the

13 Meyerhoff DJ, MacKay S, Bachman L, et al. Reduced brain $\mathrm{N}$-acetylaspartate suggests neuronal loss in cognibrain $\mathrm{N}$-acetylaspartate suggests neuronal loss in cognitively impaired human immunodeficiency virusseropositive individuals: in vivo ${ }^{1} \mathrm{H}$ magnetic resin

14 McArthur JC, Marshall DW, Brey RL, et al. Spectrum of cerebrospinal fluid findings in various stages of human immunodeficiency virus infection. Arch Neurol 1988;45:954-8.

15 Marshall DW, Brey RL, Cahill WT, Houk RW, Zajac RA, Boswell RN. Spectrum of cerebrospinal fluid findings in various stages of human immunodeficiency virus infection. Arch Neurol 1988;45:954-8.

16 Hollander $\mathrm{H}$. Cerebrospinal fluid normalities and abnormalities in individuals infected with human immunodemalities in individuals infected with human in

17 McArthur JC, Cohen BA, Farzedegan H, et al. Cerebrospinal fluid abnormalities in homosexual men with and spinal fluid abnormalities in homosexual men with and without neuropsychiatric

18 Resnick L, Berger J, Shapshak P, Tourtellotte WW Early penetration of the blood-brain barrier by HIV Neurology 1988;38:9-14.

19 Brew BJ, Bhalla RV, Paul M, et al. CSF neopterin in HIV-1 infection. Ann Neurol 1990;28:556-60.

20 Brew BJ, Bhalla RB, Paul M, et al. Cerebrospinal fluid $\beta$ microglobulin in patients with aids dementia complex an expanded series including response to zidovudine treatment. AIDS 1992;6:461-5.

21 Fuchs D, Chiodi F, Albert J, et al. Neopterin concentrations in cerebrospinal fluid and serum of individuals infected with HIV-1. AIDS 1989;3:285-8.

22 Sonnerborg A, von Stedingk L-K, Hansson L-O Strannegard $O$. Elevated neopterin and beta-2 microglobulin levels in blood and cerebrospinal fluid occur early in HIV-1 infection. AIDS 1989;3:277-83.

23 Heyes MP, Brew BJ, Martin A, et al. Increased cerebrospinal fluid concentrations of the excitotoxin quinolinic acid in human immunodeficiency virus infection and AIDS dementia complex. Ann Neurol 1991;29. 202-9.

24 Grimaldi LM, Martino GV, Franciotta DM, et al. Elevated alpha tumour necrosis factor levels in spinal fluid from HIV-1 infected patients with central nervous system involvement. Ann Neurol 1991;29:21-25.

25 Gallo P, Frei K, Rordorf C, Lazdins J, Tavolato B Fontana A. Human immunodeficiency virus type 1 Fontana A. Human immunodeficiency virus type (HIV-1) infection of the central nervous system: an
evaluation of cytokines in cerebrospinal fluid. $\mathcal{F}$ Neuroimmunol 1989;23:109-16.

26 Mastroianni CM, Liuzzi GM, Jirillo E, Vullo V, Delia S Riccio P. Cerebrospinal fluid markers for the monitoring of AIDS dementia complex severity; usefulness of antimyelin basic protein antibody detection. AIDS 1991;5:464-5.

27 Portegies P, Epstein LG, Hung STA, de Gans J, Goudsmit J. Human Immunodeficiency Virus Type antigen in cerebrospinal fluid correlation with clinical neurologic status. Arch Neurol 1989;46:261-4.

28 Brew BJ, Paul M, Khan A, Gallardo M, Price RW Detection of HIV-1 in cerebrospinal fluid: correlation with presence and severity of the AIDS dementia comwith presence and severity of the AIDS dementia com-
plex. V International Conference on AIDS, Montreal plex.

29 Chiodi F, Albert J, Olausson E, et al. Isolation frequency of Human Immunodeficiency Virus from cerebrospina fluid and blood of patients with varying severity of HIV infection. AIDS Research and Human Retroviruses 1988;4:351-8.

30 Goswami KK, Miller RF, Harrison MJ, Hamel DJ, Daniels RS, Tedder RS. Expression of HIV-1 in the cerebrospinal fluid detected by the polymerase chain reaction and its correlation with central nervous system disease. AIDS 1991;5:797-803.

31 Shaunak S, Albright RE, Klotman ME, Henry SC, Bartlett JA, Hamilton JD. Amplification of HIV-1 provirus from cerebrospinal fluid and its correlation provirus from cerebrospinal fluid and its correlation

32 Currie JE, Benson E, Ramsden D, Cooper DA. Eye movement abnormalities as a predictor of the acquired movement abnormalities as a predictor of the acquired
immunodeficiency syndrome dementia complex. Arch immunodeficiency synd

33 Sweeney J, Brew BJ, Keilp J, et al. Impairment of smooth pursuit in human immunodeficiency virus infection and its relationship to AIDS dementia complex. $f$ Psychiatr Neurosci 1991;16(5):247-52.

34 Merrill PT, Paige GD, Abrams RA, Jacoby RG, Clifford DB. Ocular motor abnormalities in human immunodeficiency virus infection. Ann Neurol 1991;30:130-8.

35 Pagano MA, Cahn PE, Garau ML, et al. Brain stem auditory evoked potentials in human immunodeficiency seropositive patients with and without acquired immunodeficiency syndrome. Arch Neurol 1992;49: 166-9. 
36 Koralnik IJ, Beaumanoir A, Hausler R, et al. A controlled study of neurologic abnormalities in men with asymptomatic immunodeficiency virus infection. $N$ Engl $\mathcal{F}$ Med 1990;323:864-70.

37 Goodin DS, Aminoff MJ, Chernoff DN, Hollander $\mathrm{H}$. Long latency event-related potentials in patients infected with human immunodeficiency virus. Ann Neurol 1990;27:414-9.

38 Parisi A, Di Perri G, Stroselli M, Nappi G, Minoli L, Rondanelli EG. Usefulness of computerised electroenRondanelli EG. Usefulness of computerised electroen-
cephalography in diagnosing, staging and monitoring cephalography in diagnosing, staging and monitor
AIDS dementia complex. AIDS 1989;3:209-13.

39 Nuwer MR, Miller EN, Visscher BR, et al. Asymptomatic HIV infection does not cause EEG abnormalities: results from the multicentre AIDS cohort study (MACS). Neurology 1992;42:1214-9.

40 Budka $\mathrm{H}$, Wiley CA, Kleihues $\mathrm{P}$, et al. HIV associated disease of the nervous system: review of nomenclature and proposal for neuropathology based terminology. Brain Pathol 1991;1:143-52.

41 Navia B, Cho ES, Petito CK, Price RW. The AIDS dementia complex: II. Neuropathology. Ann Neurol 1986;19:525-35.

42 Kure K, Weidenheim KM, Lyman WD, Dickson DW. Morphology and distribution of HIV-1 gp41-positive microglia in subacute AIDS encephalitis. Acto Neuropathol (Berl) 1990;80:393-400.

43 Shapshak P, Yoshioka M, Sun NCJ, et al. HIV-1 in postmortem brain tissue from patients with AIDS: a comparison of different detection techniques. AIDS 1992;6:915-23.

44 Michaels J, Price RW, Rosenblum MK. Microglia in the giant cell encephalitis of acquired immune deficiency syndrome: proliferation, infection and fusion. Acta syndrome: proliferation, infection

45 Kure K, Lymann WD, Weidenheim KM, Dickson DW. Cellular localization of an HIV-1 antigen in subacute AIDS encephalitis using an improved double-labelling immunohistochemical method. Am f Pathol 1990;136: 1085-92.

46 Brinkmann R, Schwinn A, Narayan O, et al. Human immunodeficiency virus infection in microglia: correlation between cells infected in the brain and cells cultured from infectious brain tissue. Ann Neurol 1992;31:361-5.

47 Achim CL, Morey M, Wiley CA. Expression of major histocompatibility complex and HIV antigens within histocompatibility complex and HIV antigens within
the brains of AIDS patients. AIDS 1991;5:535-41.

48 Mizusawa H, Hirano A, Llena JF, Shintaku $M$. Cerebrovascular lesions in acquired immune deficiency syndrome (AIDS). Acta Neuropathol (Berl) 1989; 76:51-7.

49 Yankner BA, Skolnik PR, Shoukimas GM, Gabuzda DH, Sobel RA, Ho DD. Cerebral granulomatous angiitis associated with isolation of human T-lymphotropic virus type III from the central nervous system. Ann Neurol 1986;20:362-4.

50 Cronin KC, Rosenblum M, Brew BJ, Price RW. HIV-1 brain infection: distribution of infection and clinical correlates. Abstract WCP 45 Vth International Conference on AIDS, Montreal 1989.

51 Sidtis JJ, Gatsonis C, Price RW, et al. Zidovudine treatment of the AIDS dementia complex: results of a ment of the AIDS dementia complex: results of

52 Schmitt FA, Bigley JW, McKinnis R, et al. Neuropsychological outcome of zidovudine (AZT) treatment of patients with AIDS and AIDS related complex. $N$ Eng f Med 1988;319:1573-8.

53 Portegies P, de Gans J, Lange JMA, et al. Declining incidence of AIDS dementia complex after introduction of zidovudine treatment. BMF 1989;299:819-21.

54 Butler KM, Husson RN, Balis FM, et al. Dideoxyinosine in children with symptomatic human immunodeficiency virus infection. $N$ Eng $\Im$ Med 1991;324:137-44.

55 Boucher CA, Lange JMA, Miedema FF, et al. HIV-1 biological phenotype and the development of zidovudine resistance in relation to disease progression in dine resistance in relation to disease progression in asymptomatic ind

56 Gray F, Geny C, Dournon E, Fenelon G, Lionne F, Gherard R. Neuropathological evidence that zidovudine reduces the incidence of HIV infection of the brain. Lancet 1991;337.

57 Vago L, Castagna A, Lazzarin A, Trabattoni G, Cinque $P$, Costanzi G. Reduced frequency of HIV-induced brain lesions in AIDS patients treated with zidovudine. f AIDS 1993;6:42-45.

58 Grant I, Atkinson J, Hesselink JR, et al. Evidence for early central nervous system involvement in the acquired immunodeficiency syndrome (AIDS) and other human immunodeficiency virus (HIV) infections: Studies with neuropsychologic testing and magnetic Studies with neuropsychologic testing and magnetic

resonance imaging. Ann Intern Med 1987;107:828-36.
59 Wilkie FL, Eisdorfe C, Morgan R, Lowenstein DA, Szapocznik J. Cognition in early Human immunodeficiency virus infection. Arch Neurol, 1990;47: 433-40. 60 Miller EN, Selnes OA, McArthur JC, et al. homosexual men: The Multicentre AIDS cohort Study (MACS). Neurology 1990;40:197-203.

61 Janssen RS, Saykin AJ, Cannon L, et al. Neurological and neuropsychological manifestations of HIV-1 infection: association with AIDS-related complex but not asymptomatic HIV-1 infection. Ann Neurol
1989;26:592-600

62 Chiodi F, Sonnerborg A, Albert J, et al. Human immunodeficiency virus infection of the brain. I. Virus isolation and detection of HIV specific antibodies in the cerebrospinal fluid of patients with varying clinical conditions. $\mathcal{F}$ Neurol Sci 1988;85:245-57.

63 Gray F, Lescs M, Keohane C, et al. Early brain changes in HIV infection: neuropathological study of $11 \mathrm{HIV}$ seropositive, non-AIDS cases. $\mathcal{F}$ Neuropathol Exp Neurol 1992:51:177-85.

64 McArthur JC. Neurological manifestations of AIDS Medicine (Baltimore) 1987;66:407-37.

65 Koyanagi Y, Miles S, Mitsuyasu R, et al. Dual infection of the central nervous system by AIDS viruses with distinct cellular tropisms. Science 1987;236:819-22.

$66 \mathrm{Li} \mathrm{Y,} \mathrm{Kappes} \mathrm{JC,} \mathrm{Conway} \mathrm{JA,} \mathrm{Price} \mathrm{RW,} \mathrm{Shaw} \mathrm{GM,}$ Hahn B. Molecular characterisation of human immunodeficiency virus type 1 cloned from uncultured brain tissue: identification of replication competent and defective viral genomes. $\mathcal{F}$ Virol 1991;65:3973-85.

67 Watkins BA, Dorn HH, Kelly WB, et al. Specific tropism of HIV-1 for microglial cells in primary human brain cultures. Science 1990;249:549-53.

68 Cheng-Mayer C, Weiss C, Seto D, Levy JA. Isolates of human immunodeficiency virus type 1 from the brain may constitute a special group of the AIDS virus. Proc Nat Acad Sci 1989;86:8575-9.

69 Evans L, Hurran L, Mooney J, Penny R, Cooper DA, Brew BJ. The correlation between AIDS dementia complex and the presence of macrophage tropic viruses in the cerebrospinal fluid of patients infected with HIV-1. Abstract 7th International conference on AIDS, Florence June 1991.

70 Matsuyama T, Kobayashi N, Yamamoto N. Cytokiness and HIV-1 infection: is AIDS a tumour necrosis factor and HIV-1 infection: is AIDS a
disease. AIDS 1991;5:1405-17.

71 Budka $H$. Human immunodeficiency virus (HIV) envelope and core proteins in CNS tissues of patients with the acquired immune deficiency syndrome (AIDS). Acta Neuropathol (Berl) 1990;79:611-9.

72 Harouse JM, Wroblewska Z, Lauglin $M$, et al. Human choroid plexus cells can be latently infected with human immunodeficiency virus. Ann Neurol 1989;25:406-11.

73 Gabuzda DH, Ho DD, de la Monte S, et al. Immunohistochemical identification of HTLVIII antigen in the brains of patients with AIDS. Ann Neurol gen in the brain

74 Achim CL, Schrier RD, Wiley CA. Immunopathogenesis of HIV encephalitis. Brain Pathol 1992;1:177-84

75 Lassman H, Zimprich F, Vass K, Hickey WF. Microglial cells are a component of the perivascular glia limitans. f Neurosci 1991;28:236-43.

76 Gyorkey F, Melnick JL, Gyorkey P. Human immunodeficiency virus in brain biopsies of patients with AIDS and progressive encephalopathy. $\mathcal{F}$ Infect Dis 1987;155:870-6.

77 Stoler MH, Eskin TA, Benn S, Angerer RC, Angerer LM. Human T-cell lymphotropic virus type III infection of the central nervous system. A preliminary in situ analysis. $\mathscr{f} A M A 1986 ; 256: 2360-4$.

78 Budka $\mathrm{H}$, Lassman $\mathrm{H}$. Human immunodeficiency virus in glial cells? f Infect Dis 1988;157:203.

79 Sharer LR, Prineas JW. Human immunodeficiency virus in glial cells continued. F Infect Dis 1988;157:204

80 Esiri M, Morris CS, Millard PR. Fate of oligodendrocytes in HIV-1 infection. AIDS 1991;5:1081-8.

81 Dewhurst $S$, Bresser J, Stevenson $M$, et al. Susceptibility of human glial cells to infection with human immuno-
deficiency virus (HIV). FEBS LETTS 1987;213: 138-43.

82 Christofinis G, Papadaki L, Sattentau Q, Ferns RB, Tedder R. HIV replicates in cultured human brain cells: $A I D S$ 1987;1:229-34.

83 Clapham PR, Weber JN, Whitby D, et al. Soluble CD4 blocks the infectivity of diverse strains of HIV and SIV for $T$ cells and monocytes but not for brain and muscle cells. Nature 1989;337:368-70.

84 Harouse JM, Bhat S, Spitalnik SL, et al. Inhibition of entry of HIV-1 in neural cell lines by antibodies against galactosyl-ceramide. Science 1991;253:320-3.

85 Tyor W, Glass JD, Griffin JW, et al. Cytokine expression in the brain during the acquired immune deficiency syndrome. Ann Neurol 1992;31:349-60.

86 Vazeux R, Lacroix-Ciaudo C, Blanche S, et al. Low levels of human immunodeficiency virus replication in the brain tissue of children with severe acquired immunodeficiency syndrome encephalopathy. Am $₹$ Pathol 1992;140:137-44

87 Pang S, Koyanagi Y, Miles S, Wiley C, Vinters HV, Chen ISY. High levels of unintegrated HIV-1 DNA in brain tissue of AIDS dementia patients. Nature 1990;343:5-8.

88 Gadler H, Hahn BH, Shaw GM, Brew BJ, Rosenblum $M$, Price RW. Analysis of brain from AIDS patients for HIV-1 DNA sequences using the polymerase chain reaction. Abstract WCP 84 Vth International Conference on AIDS, Montreal 1989.

89 Epstein LG, Kuiken C, Blumberg BM, et al. HIV-1 V3 domain variation in brain and spleen of children with AIDS: tissue specific evolution within host determined quasispecies. Virology 1991;180:583-90.

90 Haase AT. Pathogenesis of lentivirus infections. Nature 1986;322:130-6.

91 Peluso R, Haase A, Stowring L, Edwards M, Ventura P. 
A trojan horse mechanism for the spread of visna virus in monocytes. Virology 1985;147:231-6.

92 Petito CK, Cash KS. Blood brain barrier abnormalities in the acquired immune deficiency syndrome: immunohistochemical localization of serum proteins in postmortem brain. Ann Neurol 1992;32:658-66.

93 Rhodes R. Evidence of serum-protein leakage across the blood-brain barrier in the acquired immunodeficiency syndrome. 7 Neuropathol Exp Neurol 1991;50:171-83.

94 Brenneman DE, Westbrook GL, Fitzgerald S, et al. Neuronal cell killing by the envelope protein of HIV and its prevention by vasoactive intestinal peptide. and its prevention by

95 Lipton SA. Requirement for macrophages in neuronal injury induced by HIV envelope glycoprotein gp 120 . Neuroreport 1992;3:913-5.

96 Dawson VL, Dawson TM, Uhl GR, Snyder S. Human immunodeficiency virus type 1 coat protein neurotoxicity mediated by nitric oxide in primary cortical cultures. Proc Natl Acad Sci 1993;90:3256-9.

97 Giulian D, Vaca K, Noonan C. Secretion of neurotoxins by mononuclear phagocytes infected with HIV-1. Science 1990;250:1593-6.

98 Genis P, Jett M, Bernton EW, et al. Cytokines and arachidonic acid metabolites produced during HIVinfected macrophage-astroglial interactions: implications for the neuropathogenesis of HIV disease. $\mathcal{F}$ Exp Med 1992;176:1703-18.

99 Brew BJ, Corbeil J, Pemberton L. Quinolinic acid and the pathogenesis of AIDS dementia complex. VII International Conference on AIDS Amsterdam 19-24 July 1992 .

100 Brew BJ, Pemberton L, Evans L, Heyes M. Quinolinic acid production by macrophages infected with demented and non-demented isolates of HIV. Abstract 2716, IXth International conference on AIDS IVth STD World Congress Berlin June 6-11 1993.

101 Keating JN, Trimble KC, Mulchay F, Scott JM, Weir DG. Evidence of brain methyltransferase inhibition and early brain involvement in HIV positive patients. Lancet 1991;337:935-9.

102 Petito CK, Navia BA, Cho ES, Jordan BD, George DC Price RW. Vacuolar myelopathy pathologically resembrice $R$ w. Vacuolar myelopathy pathologically resembling subacute combined degeneration in patients with acquired immunodeficie

103 Sharer LR, Dowling PC, Michaels J, et al. Spinal cord disease in children with HIV-1 infection: a combined molecular biological and neuropathological study. Neuropathol Appl Neurobiol 1990;16:317-31.

104 Rosenblum M, Scheck AC, Cronin KC, et al. Dissociation of AIDS related vacuolar myelopathy and productive HIV-1 infection of the spinal cord. Neurology 1989;39:892-6.

105 Grafe MR, Wiley CA. Spinal cord and peripheral nerve pathology in AIDS: the roles of cytomegalovirus and
human immunodeficiency virus. Ann Neurol 1989;25: 561-6.

106 Budka H, Maier H, Pohl P. Human immunodeficiency virus in vacuolar myelopathy of the acquired immuno-

107 Weiser B, Peress N, La Neve D, Eilbott DJ, Seidman R Weiser B, Peress N, La Neve D, Eilbott DJ, Seidman R,
Burger H. Human immunodeficiency virus type 1 expression in the central nervous system correlates directly with extent of disease. Proc Natl Acad Sci 1990;87:3997-401.

108 Kamin SS, Petito CK. Ideopathic myelopathy with white matter vacuolation in non-acquired immunodeficiency syndrome patients. Hum Pathol 1991;22:816-24.

109 Gessain A, Vernant JC, Maurs L, et al. Antibodies to human T-lymphotropic virus type $I$ in patients with tropical spastic paraparesis. Lancet 1985;2:407-10.

110 Osame M, Usuku K, Izumo S, et al. HTLV-I associated myelopathy: a new clinical entity. Lancet 1986;1: 1031-2.

111 Jacobson $S$, Lehky $T$, Nishimura $M$, Robinson $S$ McFarlin DE, Dhib-Jalbut S. Isolation of HTIV-II from a patient with chronic progressive neurological from a patient with chronic progressive neurological disease clinically indistinguishable from HTLV-I associated myelopathy/tropic

112 Harrington WJ, Sheremata W, Hjelle B, et al. Spastic ataxia associated with human $T$-cell lymphotropic virus type II infection. Ann Neurol 1993;33:411-4.
113 Brew BJ, Hardy W, Zuckerman E, et al. AIDS related vacuolar myelopathy is not associated with coinfection by HTLV-I. Ann Neurol 1989;26:679-81.

114 Surtees R, Hyland K, Smith I. Central nervous system methyl-group metabolism in children with neurological complications of HIV infection. Lancet 1990;335: 619-21.

115 Simpson DM, Wolfe DE. Neuromuscular complications of HIV infection and its treatment. AIDS 1991;5: 917-26.

116 Lipkin WI, Parry G, Kiprov D, et al. Inflammatory neuropathy in homosexual men with lymphadenopathy. Neurology 1985:35:1479-83.

117 Said G, Lacroix C, Chemouilli P, et al. CMV neuropathy in acquired immunodeficiency syndrome: a clinical and pathological study. Ann Neurol 1991;29:139-46.

118 Cornblath DR, McArthur JC, Kennedy PGE, Witte AS Griffin JW. Inflammatory demyelinating periphera neuropathies associated with human T-cell lymphotropic virus type III infection. Ann Neurol 1987;21:32-40.

119 Brew BJ, Miller J. Human immunodeficiency related headache. Neurology 1993;43:1048-1100.

120 Gherardi R, Lebargy F, Gaulard P, et al. Necrotising vasculitis and HIV replication in peripheral nerves. N Eng f Med 1989;321:685-6.

121 Freeman R, Roberts M, Friedman L, Broadbridge C. Autonomic function and human immunodeficiency virus infection. Neurology 1990;40:575-80.

122 Cohen JA, Laudenslager M. Autonomic nervous system involvement in patients with human immunodeficiency virus infection. Neurology 1989;39:1111-2.

123 So YT, Holtzman DM, Abrams DI, Olney RK Peripheral neuropathy associated with AIDS. Arch Neurol 1988;45:945-8.

124 Mah V, Vartavarian LM, Akers MA, Vinters H. Abnormalities of peripheral nerve in patients with HIV infection. Ann Neurol 1988;24:713-7.

125 Cornblath DR. Treatment of the neuromuscular complications of human immunodeficiency virus infection. Ann Neurol 1988;23(suppl):S88-S91.

126 de la Monte SM, Gabuzda DH, Ho D, et al. Periphera neuropathy in the acquired immunodeficiency syndrome.

127 Fuller GN, Jacobs JM, Guiloff RJ. Association of painful peripheral neuropathy in AIDS with cytomegalovirus infection. Lancet 1989;i:937-41.

128 Layzer R. Mycloneuropathy after prolonged exposure to nitrous oxide. Lancet 1978;ii:1227-30.

129 Griffin JW, Li CY, Tyor WR, et al. Macrophage phenotypes in peripheral nerves of HIV-1 infected individuals. Abstract Neu-14 Neurological and Neuropsychological complications of HIV infection. Monterey 1990.

130 Simpson DM, Bender AN. Human immunodeficiency virus-associated myopathy: analysis of 11 patients. Ann veurol 1988;24:79-84.

131 Dalakas MC, Pezeshkpour GH, Gravell M, et al. Polymyositis associated with AIDS retrovirus. $¥ A M A$ 1986;256:2381-3.

132 Wong MC, Suite NA, Labar DR. Seizures in human immunodeficiency virus infection. Arch Neurol 1990;47:640-2.

133 Holtzman DM, Kaku DA, So YT. New onset seizure associated with human immunodeficiency virus infection: causation and clinical features in 100 cases. $A m \mathcal{F}$ Med 1989;87:173-7.

134 Lipton SA. Models of neuronal injury in AIDS: another role for the NMDA receptor? Trends Neurosci 1992;15:75-9.

135 Engstrom JW, Lowenstein DH, Bredesen DE. Cerebral infarctions and transient neurologic deficits associated with acquired immunodeficiency syndrome. Am $₹ \mathrm{Med}$ with acquired imm

136 Brew BJ, Miller J. Transient ischaemic attacks in HIV-1 infection. Abstract 2712, IXth International conference on AIDS IVth STD World Congress Berlin June 6-11 1993.

137 Mizusawa H, Hirano J, Llena JF, Shintaku M. Cerebra lesions in acquired immune deficiency syndrome (AIDS). Acta Neuropathol (Berl) 1988;76:451-7.

138 Maclean C, Flegg PJ, Kilpatrick DC. Anti-cardiolipin antibodies and HIV infection. Clin Exp Immunol 1990;81:263-6. 